\title{
Low-dose dexamethasone effectively prevents postoperative nausea and vomiting after ambulato- ry laparoscopic surgery
}

[Une faible dose de dexaméthasone prévient efficacement les nausées et les vomissements postopératoires en chirurgie laparoscopique ambulatoire]

Jeng-Chai Huang PhD, ${ }^{*}$ Ja-Ping Shieh MD Ms, $†$ Chao-Shun Tang PhD, $\ddagger$ Jann-Inn Tzeng MD, $\ddagger$ Koung-Shing Chu MD, $\ddagger$ Jhi-Joung Wang MD DMs* $\dagger$

Purpose: To evaluate the prophylactic effect of low-dose dexamethasone ( $5 \mathrm{mg}$ ) on postoperative nausea and vomiting (PONV) in women undergoing ambulatory laparoscopic surgery. Metoclopramide and saline served as controls.

Methods: One hundred twenty women ( $n=40$ in each of the three groups) undergoing ambulatory laparoscopic tubal ligation under general anesthesia were enrolled in this randomized, double-blinded, placebo-controlled study. After tracheal intubation, group I received iv dexamethasone $5 \mathrm{mg}$, whereas groups II and III received iv metoclopramide $10 \mathrm{mg}$ and saline, respectively.

Results: Patients in group I reported a lower incidence of PONV and requested less rescue antiemetics than those in group III during the first four postoperative hours $(P<0.0 \mathrm{I})$. Patients in group I reported a lower incidence of PONV than those in groups II ( $P$ $<0.05)$ and III $(P<0.0$ I $)$ during the 24 -hr postoperative period. Groups II and III did not differ from each other in the incidence of PONV and the proportion of patients who requested rescue antiemetics.

Conclusion: Prophylactic iv dexamethasone $5 \mathrm{mg}$ significantly reduces the incidence of PONV in women undergoing ambulatory laparoscopic tubal ligation. At this dose, dexamethasone is more effective than metoclopramide $10 \mathrm{mg}$ or placebo.

Objectif : Évaluer l'effet prophylactique d'une faible dose de dexaméthasone (5 mg) sur les nausées et vomissements postopératoires (NVPO) chez des patientes de chirurgie laparoscopique ambulatoire. Le métoclopramide et une solution salée ont servi de témoins.

Méthode: Cent vingt femmes ( $n=40$ dans chacun des trois groupes formés de façon aléatoire), devant subir une ligature des trompes sous anesthésie générale en chirurgie laparoscopique ambulatoire, ont participé à l'étude randomisée, en double insu et contrôlée contre placebo. Après l'intubation endotrachéale, les patientes du groupe I ont reçu $5 \mathrm{mg}$ de dexaméthasone iv tandis que celles des groupes II et III ont reçu $10 \mathrm{mg}$ de métoclopramide ou de solution salée iv, respectivement.

Résultats : Les patientes du groupe I ont signalé une plus faible incidence de NVPO et ont demandé moins d'antiémétiques de secours que les patientes du groupe III pendant les quatre premières heures postopératoires $(P<0,01)$. Les patients du groupe I ont eu moins de NVPO que celles des groupes II $(P<0,05)$ et III $(P<0,0$ I) pendant une période de $24 \mathrm{~h}$ après l'intervention. Aucune différence intergroupe quant à l'incidence de NVPO et au nombre de patientes qui ont eu recours aux antiémétiques n'a été notée entre les patientes des groupes II et III.

Conclusion : L'administration iv de $5 \mathrm{mg}$ de dexaméthasone réduit significativement l'incidence de NVPO chez des patientes qui subissent une ligature des trompes en chirurgie laparoscopique ambulatoire. C'est plus efficace que $10 \mathrm{mg}$ de métoclopramide ou de placebo.

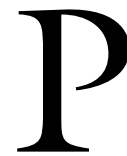

OSTOPERATIVE nausea and vomiting (PONV) is among the most unpleasant experiences associated with ambulatory surgery. ${ }^{1-4}$ The incidence of nausea and vomiting after outpatient gynecological laparoscopic surgery is particularly high, with previous reported rates of $54-92 \% .^{1-5}$ In an attempt to decrease the incidence of PONV in the ambulatory setting, a number of antiemetics have been studied. ${ }^{1-6}$ Among the

From the Department of Medical Research, ${ }^{*}$ and Anesthesiology, $†$ Chi-Mei Medical Center, Tainan; and the Department of Anesthesiology,ł Kaohsiung Medical University, Kaohsiung, Taiwan.

Address correspondence to: Dr. Jhi-Joung Wang, Department of Anesthesiology, Chi-Mei Medical Center, Tainan, Taiwan. Phone: 886 6-2517844; Fax: 886-6-2832639; E-mail: 400003@mail.chimei.org.tw

This study was performed at Chi-Mei Medical Center, Tainan, Taiwan.

Accepted for publication May 28, 2001.

Revision accepted August 1, 2001. 
antiemetics currently used, $5 \mathrm{HT}_{3}$ antagonists such as ondansetron and granisetron are increasing in popularity. Although the antiemetics are effective, the high cost of these drugs limits their widespread use. . $^{1,3,4}$ Other currently used antiemetic drugs (e.g., anticholinergics, dopamine receptor antagonists, antihistamines), although effective, possess clinically significant side effects (e.g., restlessness, dry mouth, tachycardia, and extrapyramidal symptoms). ${ }^{6-8} \mathrm{~A}$ low cost antiemetic agent with few side effects would be of benefit to anesthesiologists and their patients.

Since 1981, dexamethasone has been reported to be effective in reducing the incidence of emesis in patients undergoing chemotherapy. ${ }^{9-11}$ Recently, dexamethasone has also been reported to be effective in reducing the incidence of PONV. ${ }^{12-16}$ The commonly used dose is $8-10 \mathrm{mg}$ but the minimum effective dose is suggested to be $5 \mathrm{mg}$ for the prevention of PONV in patients undergoing thyroidectomy. ${ }^{16}$ The aim of the present study was to evaluate the prophylactic antiemetic effect of low-dose dexamethasone $(5 \mathrm{mg})$ in women undergoing ambulatory laparoscopic tubal ligation. Metoclopramide, a commonly used antiemetic, ${ }^{2}$ and saline were used as controls.

\section{Patients and methods}

After obtaining Institutional Review Board approval and written informed consent from the patients, 120 women, ASA physical status I or II, scheduled for outpatient laparoscopic tubal ligation, were enrolled in the study. Patients who were breast feeding, weighed $>90$ $\mathrm{kg}$, or who had a history of PONV, motion sickness, or had received an antiemetic within 24-hr before surgery were excluded from participation. Patients provided detailed medical histories and demographic information, including age, weight, height, drug consumption, as well as last menstrual period.

On arrival in the operating room, routine monitoring devices were placed, and baseline blood pressure, heart rate, and pulse oximetry values were recorded. Patients were, then, randomly assigned into one of the three groups ( $n=40$, each) using a computer generated random number table. Study medications totaled $2 \mathrm{~mL}$, were prepared by one of the investigators and were administered in a double-blind fashion. After tracheal intubation, group I received iv dexamethasone $5 \mathrm{mg}$, group II received $i v$ metoclopramide $10 \mathrm{mg}$, while group III received $i v$ saline. The anesthetic technique and surgical procedure were identical in all patients. Anesthesia was induced with iv propofol (2-2.5 $\left.\mathrm{mg} \cdot \mathrm{kg}^{-1}\right)$, glycopyrrolate $(0.2 \mathrm{mg})$ and fentanyl (2 $\left.\mu \mathrm{g} \cdot \mathrm{kg}^{-1}\right)$. Tracheal intubation was facilitated with $i v$ vecuronium $\left(0.15 \mathrm{mg} \cdot \mathrm{kg}^{-1}\right)$. Anesthesia was maintained with $1.0-2.5 \%$ (inspired concentration) isoflurane in oxygen. Ventilation was controlled mechanically and was adjusted to keep an end-tidal concentration of $\mathrm{CO}_{2}$ between 30 and $40 \mathrm{mmHg}$ with an anesthetic/respiratory gas analyzer (Capnomac Ultima; Datex, Helsinki, Finland). Laparoscopic tubal ligation was performed under video guidance and involved two punctures of the abdomen. During surgery, the patients were placed in a Trendelenburg position and the abdomen was insufflated with $\mathrm{CO}_{2}$ to an intra-abdominal pressure of 10-14 mmHg. At the cessation of the surgery, iv glycopyrrolate $(0.6 \mathrm{mg})$ and neostigmine $(3 \mathrm{mg})$ were administered for reversal of neuromuscular blockade, and the trachea was extubated.

After surgery, patients were transported to the postanesthetic care unit (PACU). During their stay in PACU (four hours), vital signs such as blood pressure, heart rate, and respiratory rate were monitored every $15 \mathrm{~min}$ and oxygen saturation $\left(\mathrm{SaO}_{2}\right.$; by pulse oximetry) was monitored continuously. Tenoxicam $20 \mathrm{mg}$ iv was given routinely for the prevention of postoperative pain. Pain intensity was assessed by using a $10-\mathrm{cm}$ visual analog scale (VAS; $0=$ no pain to $10=$ most severe pain). Because pain after laparoscopic tubal ligation is relatively minor, ${ }^{17}$ patients did not receive further analgesic treatment after discharge.

Nausea and vomiting were assessed immediately after operation and at one-hour intervals in the PACU for four hours. In addition, nausea and vomiting were assessed by telephone 24-hr after hospital discharge. Nausea and vomiting were evaluated on a 3-point ordinal scale $(0=$ none, $1=$ nausea, and $2=$ vomiting $)$. In the current study, no distinction was made between vomiting and retching (i.e., a retching event was considered a vomiting event). In the PACU, iv ondansetron $4 \mathrm{mg}$ was given at the patient's request (for relief of intolerable nausea, a subjective feeling which was reported by patients) or when vomiting occurred. No nausea, no vomiting and no antiemetic medication during the 24-hr postoperative period was defined as successful protection. The patients and the investigator who collected the data were blinded to the patient's group. Side effects, e.g., extrapyramidal symptoms, if present, were recorded.

Sample size was predetermined by using a power analysis based on the assumptions that (a) the total incidence of nausea and vomiting in the saline group would be $60 \%,{ }^{14}$ (b) a $40 \%$ reduction in the total incidence of nausea and vomiting (from $60 \%$ to $36 \%$ ) in the treatment group would be of clinical relevance, and (c) $\alpha=0.05$, $ß=0.2$. The analysis showed that 37 patients per group would be sufficient. A series of one-way analyses of variance were conducted to examine differences among the 
three study groups with respect to parametric variables. If a significant difference was found, the Bonferroni t test was used to detect the intergroup differences. The Kruskal-Wallis test was used to determine differences among the three groups with respect to nonparametric variables, followed by the Mann-Whitney rank-sum test for intergroup differences. Categorical variables were analyzed by using a series of $3 \times 2 \chi^{2}$ test to determine the differences among the three groups, followed by $2 \mathrm{x}$ $2 \chi^{2}$ test for intergroup differences. All follow-up analyses were corrected for the number of simultaneous contrasts using the Bonferroni adjustments. A $P$ value $<0.05$ was considered significant.

\section{Results}

Of the 120 patients enrolled in this study, three patients who did not complete the surgical procedure (laparoscopic tubal ligation) due to intra-abdominal adhesions and two patients who could not be contacted by telephone after hospital discharge were eliminated from the study. The data obtained from the remaining 115 patients were analyzed. The patients' characteristics (e.g., age, weight, and height), interval since the last menstrual period and the durations of anesthesia and surgery were similar among the groups (Table I).

In the PACU, vital signs such as blood pressure, heart rate, and respiratory rate were stable and were not different among the groups. No patients demonstrated a $\mathrm{SaO}_{2}$ below $90 \%$. The intensity of postoperative pain was relatively minor, patients in the three groups reporting a similar low VAS pain score (median; group $\mathrm{I}=1.5$; group $\mathrm{II}=2.1$; group $\mathrm{III}=2.1$ ).

The efficacy of dexamethasone as a prophylactic antiemetic compared with placebo is summarized in Table II. We used the total incidence of nausea and vomiting to present PONV. During their stay in the PACU (zero to four hours postoperatively), patients in group I reported a lower incidence of PONV than those in group III $(P<0.01$; Table II $)$. In addition, less patients in group I requested a rescue antiemetic (iv ondansetron $4 \mathrm{mg}$ ) than in group III $(P<0.01)$. During the total observation period 0-24 hr, patients in group I reported a lower incidence of PONV and a higher percentage of successful protection than those in groups II and III $(P<0.05, P<0.01$, respectively). Groups II and III did not differ from each other in the incidence of PONV, antiemetic medication and successful protection. Side effects related to the use of dexamethasone and metoclopramide were not found.

\section{Discussion}

Although the use of laparoscopy for tubal ligation has decreased surgical morbidity and has become a popu-
TABLE I Patients' characteristics

\begin{tabular}{|c|c|c|c|}
\hline & $\begin{array}{l}\text { Dexamethasone } \\
\text { (Group I) }\end{array}$ & $\begin{array}{l}\text { Metoclopramide } \\
\text { (Group II) }\end{array}$ & $\begin{array}{l}\text { Saline } \\
\text { (Group III) }\end{array}$ \\
\hline No. & 39 & 38 & 38 \\
\hline Age $(y r)$ & $32(27-35)$ & $34(31-36)$ & $35(30-37)$ \\
\hline Weight $(\mathrm{kg})$ & $54(42-72)$ & $56(46-75)$ & $56(45-76)$ \\
\hline Height $(\mathrm{cm})$ & $158(145-172)$ & $157(138-170)$ & $156(139-173)$ \\
\hline \multirow{2}{*}{\multicolumn{4}{|c|}{$\begin{array}{l}\text { Interval since last } \\
\text { menstrual period (days) }\end{array}$}} \\
\hline & & & \\
\hline $0-8$ & 12 & 11 & 11 \\
\hline $9-16$ & 7 & 9 & 10 \\
\hline $16-28$ & 11 & 12 & 9 \\
\hline$>28$ & 9 & 6 & 8 \\
\hline \multicolumn{4}{|c|}{ Duration of anesthesia } \\
\hline$(\min )$ & $65(45-78)$ & $68(49-78)$ & $64(51-76)$ \\
\hline \multicolumn{4}{|c|}{ Duration of surgery } \\
\hline$(\min )$ & $41(32-63)$ & $45(38-65)$ & $42(38-64)$ \\
\hline
\end{tabular}

Values given as numbers or median (range).

TABLE II Incidence of nausea and vomiting after laparoscopic tubal ligation

\begin{tabular}{llll}
\hline & $\begin{array}{l}\text { Dexamethasone } \\
\text { (Group I) }\end{array}$ & $\begin{array}{l}\text { Metoclopramide } \\
\text { (Group II) }\end{array}$ & $\begin{array}{l}\text { Saline } \\
\text { (Group III) }\end{array}$ \\
\hline $\begin{array}{l}\text { No. } \\
\text { In the PACU }\end{array}$ (0-4 hr postoperatively) & 38 & 38 \\
- Nausea & $6(15)$ & $8(21)$ & $12(32)$ \\
- Vomiting & $3(8)$ & $6(16)$ & $10(26)$ \\
- Total & $9(23) \dagger$ & $14(37)$ & $22(58)$ \\
- Rescue & & & \\
antiemetic & $4(10) \dagger$ & $10(26)$ & $16(42)$ \\
After discharge & $(4-24$ hr postoperatively) & \\
- Nausea & $4(10)$ & $6(15)$ & $8(21)$ \\
- Vomiting & $1(3)$ & $4(11)$ & $3(8)$ \\
- Total & $5(13)$ & $10(26)$ & $11(29)$ \\
From 0-24 br postoperatively & & \\
- Nausea & $8(21)$ & $12(32)$ & $13(34)$ \\
- Vomiting & $3(8)$ & $8(21)$ & $11(29)$ \\
- Total & $11(28)^{*} \dagger$ & $20(53)$ & $24(63)$ \\
$\begin{array}{l}\text { Successful } \\
\text { protection }\end{array}$ & $28(72)^{*} \dagger$ & $18(47)$ & $14(37)$ \\
\hline
\end{tabular}

Values are numbers of patients (\%). PACU=postanesthetic care unit. Successful protection was defined as no nausea, no vomitin and no antiemetic medication. ${ }^{*} P<0.05$ when compared with group II; $\uparrow P<0.01$ when compared with group III using $3 \times 2 \chi^{2}$ test followed by $2 \times 2 \chi^{2}$ test.

lar procedure in an ambulatory setting, ${ }^{18,19}$ a high incidence of PONV (54-92\%) has been reported. ${ }^{1-5}$ In our study, we found that the total incidence of PONV was $63 \%$ within $24-\mathrm{hr}$ postoperatively in patients undergoing laparoscopic tubal ligation when no antiemetic was given prophylactically. After pretreatment with low-dose of dexamethasone $5 \mathrm{mg}$, the incidence of PONV was reduced to $28 \%$. We also 
found that dexamethasone $5 \mathrm{mg}$ was more effective than metoclopramide $10 \mathrm{mg}$ and saline in preventing PONV in women undergoing ambulatory laparoscopic tubal ligation.

Several studies have demonstrated dexamethasone's efficacy and minimal adverse events in the prevention of nausea and vomiting associated with chemotherapy. ${ }^{9-11}$ Dexamethasone has also been found to be effective in the prevention of PONV. ${ }^{12-16}$ Among the doses used, 8-10 $\mathrm{mg}$ dexamethasone has been used most frequently in the prevention of PONV. ${ }^{12-15}$ Although a $2.5-\mathrm{mg}$ dose was suggested to be the minimum effective dose for PONV in patients undergoing major gynecologic surgery, ${ }^{20}$ it was only partially effective for this purpose in patients undergoing thyroidectomy. ${ }^{16}$ A 5-mg dose was found to be effective in both situations. ${ }^{16,20}$ Therefore, a $5 \mathrm{mg}$ dose of dexamethasone was chosen in the present study.

The etiology of PONV in patients undergoing laparoscopic tubal ligation is not fully understood. Risk factors such as a residual pneumoperitoneum after $\mathrm{CO}_{2}$ insufflation, ${ }^{21}$ intraoperative use of isoflurane and fentanyl, 8,22 appearance of postoperative pain, ${ }^{8,17,22}$ and difference in the phase of menstrual cycle $^{5}$ may all contribute to these episodes. In the present study, all of these factors were controlled by study design. All patients underwent laparoscopic tubal ligation with a standardized surgical procedure and anesthetic regimen. As predicted, the duration of surgery, anesthesia and the anesthetics used were similar among the groups. In addition, the phase of menstrual cycle and the intensity of postoperative pain were also similar among the groups. Therefore, it is likely the differences in the incidence of PONV among the groups can be attributed to the study drugs rather than to any confounding variable.

Surprisingly, metoclopramide $10 \mathrm{mg}$ did not prevent the occurrence of PONV and did not reduce the proportion of patients who requested rescue antiemetics. Metoclopramide, a dopamine and serotonin receptor antagonist, was discovered almost 40 years ago and is known as an antiemetic since the 1960 s. $^{2,7,23}$ It is still used widely in clinical practice. Metoclopramide $10 \mathrm{mg}$ $i v$ is suggested to be the optimal dose for PONV, although much higher doses have been used for the prevention of chemotherapy-related emesis. ${ }^{23}$ Recently, a systematic review of metoclopramide stated that the drug does not protect against nausea or late vomiting. ${ }^{23}$ The anti-vomiting effect of metoclopramide appears to be present only during the first six hours following administration. ${ }^{23}$ In the present study, metoclopramide was administered at the beginning of surgery for the evaluation of its prophylactic antiemetic properties and was found to reduce PONV by $21 \%$ when compared to saline during the first four hours postoperatively (around five hours after administration). However, the difference was not significant. This result may be explained by its relatively weak antiemetic effect.

Side effects related to the use of dexamethasone and metoclopramide were not found. Multiple-dose corticosteroid therapy (> one week) may cause side effects, such as increased risk of infection, glucose intolerance, delayed wound healing, superficial ulceration of the gastric mucosa, etc. ${ }^{24}$ However, these side effects are not found after a single dose of dexamethasone 8-10 mg. ${ }^{12-16}$ In our study, a single and relative low-dose of dexamethasone $5 \mathrm{mg}$ were used and no discernible side effects were found. Metoclopramide-related side effects, such as extrapyramidal symptoms, have been reported. However, the incidence is very low $(<1 \%)^{7,23}$ In our study, no metoclopramide-related extrapyramidal symptoms were found.

Cost is an ever-increasing concern in today's health care system. Both of the prophylactic antiemetics we used are relatively inexpensive. Dexamethasone $5 \mathrm{mg}$ costs \$18 new Taiwan dollars (NT), whereas metoclopramide $10 \mathrm{mg}$ costs $\$ 5 \mathrm{NT}$. This is remarkably less expensive than a similar and effective dose of an alternate antiemetic, ondansetron, which costs \$450 NT for a 4-mg dose. This is why ondansetron was not chosen as our first-line prophylactic antiemetic.

In summary, prophylactic $i v$ administration of lowdose dexamethasone $5 \mathrm{mg}$ significantly reduced the incidence of PONV in women undergoing ambulatory laparoscopic tubal ligation. It was more effective than metoclopramide $10 \mathrm{mg} i v$ or placebo. Dexamethasone $5 \mathrm{mg}$ appears to be a cost-effective alternative for the prevention of PONV in women undergoing ambulatory laparoscopic tubal ligation.

\section{References}

1 Bodner M, White PF. Antiemetic efficacy of ondansetron after outpatient laparoscopy. Anesth Analg 1991; 73: 250-4.

2 Pandit SK, Kothary SP, Pandit UA, Randel G, Levy L. Dose-response study of droperidol and metoclopramide as antimetics for outpatient anesthesia. Anesth Analg 1989; 68: 798-802.

3 Sniadach MS, Alberts MS. A comparison of the prophy lactic antiemetic effect of ondansetron and droperidol on patients undergoing gynecologic laparoscopy. Anesth Analg 1997; 85: 797-800.

4 Raphael JH, Norton AC. Antiemetic efficacy of prophylactic ondansetron in laparoscopic surgery: random ized, double-blind comparison with metoclopramide. Br J Anaesth 1993; 71: 845-8. 
5 Honkavaara P, Lebtinen A-M, Hovorka J, Korttila K. Nausea and vomiting after gynaecological laparoscopy depends upon the phase of the menstrual cycle. Can J Anaesth 1991; 38: 876-9.

6 Melnick B, Sawyer R, Karambelkar D, Phitayakorn P, Uy NTL, Patel R. Delayed side effects of droperidol after ambulatory general anesthesia. Anesth Analg 1989; 69: 748-51.

7 Jiménez-Jiménez FJ, Garcia-Ruiz PJ, Molina JA. Druginduced movement disorders. Drug Safety 1997; 16 : 180-204.

8 Watcha MF, White PF. Postoperative nausea and vomit ing. Its etiology, treatment, and prevention. Anesthesiology 1992; 77: 162-84.

9 Aapro MS, Alberts DS. Dexamethasone as an antiemetic in patients treated with cisplatin (Letter). $\mathrm{N}$ Engl Med 1981; 305: 520.

10 Sekine I, Nishiwaki $\Upsilon$, Kakinuma R, et al. Phase II study of high-dose dexamethasone-based association in acute and delayed high-dose cisplatin-induced emesis-JCOG study 9413. Br J Cancer 1997; 76: 90-2.

11 Italian Group for Antiemetic Research. Dexamethasone, granisetron, or both for the prevention of nausea and vomiting during chemotherapy for cancer. $\mathrm{N}$ Engl J Med 1995; 332: 1-5.

12 Pappas ALS, Sukbani R, Hotaling AJ, et al. The effect of preoperative dexamethasone on the immediate and delayed postoperative morbidity in children undergoing adenotonsillectomy. Anesth Analg 1998; 87: $57-61$

13 Splinter W, Roberts DJ. Prophylaxis for vomiting by children after tonsillectomy: dexamethasone versus perphenazine. Anesth Analg 1997; 85: 534-7.

14 Wang JJ, Ho ST, Liu HS, Ho CM. Prophylactic antiemetic effect of dexamethasone in women undergoing ambulatory laparoscopic surgery. $\mathrm{Br} \mathrm{J}$ Anaesth 2000; 84: 459-62.

15 Fujii $\Upsilon$, Tanaka $H$, Toyooka $H$. The effects of dexamethasone on antiemetics in female patients undergoing gynecologic surgery. Anesth Analg 1997; 85: 913-7.

16 Wang JJ, Ho ST, Lee SC, Lin YC, Ho CM. The use of dexamethasone for preventing postoperative nausea and vomiting in females undergoing thyroidectomy: a dose-ranging study. Anesth Analg 2000; 91: 1404-7.

17 Alexander JI. Pain after laparoscopy. Br J Anaesth 1997; 79: 369-78

18 Wilson EW. The evolution of methods for female sterilization. Int J Gynecol Obstet 1995; 51(Suppl.1): S3-13.

19 World Health Organization. Task Force on Female Sterilization, Special Programme of Research, Development and Research Training in Human Reproduction. Minilaparotomy or laparoscopy for steril- ization: a multicenter, multinational randomized study. Am J Obstet Gynecol 1982; 143: 645-52.

20 Lin K, Hsu C-C, Chia $\Upsilon$ - $\Upsilon$. The effective dose of dexamethasone for antiemesis after major gynecological surgery. Anesth Analg 1999; 89: 1316-8.

21 Fredman B, Jedeikin R, Olsfanger D, Flor P, Gruzman $A$. Residual pneumoperitoneum: a cause of postoperative pain after laparoscopic cholecystecomy. Anesth Analg 1994; 79: 152-4.

22 Cohen MM, Duncan PG, DeBoer DP, Tweed WA. The postoperative interview: assessing risk factors for nausea and vomiting. Anesth Analg 1994; 78: 7-16.

23 Henzi I, Walder B, Tramèr MR. Metoclopramide in the prevention of postoperative nausea and vomiting: a quantitative systematic review of randomized, placebocontrolled studies. Br J Anaesth 1999; 83: 761-71.

24 Schimmer BP, Parker KL. Adrenocorticotropic hormone; adrenocortical steroids and their synthetic analogs; inhibitors of the synthesis and actions of adrenocortical hormones. In: Hardman JG, Limbrid LE, Molinoff PB, Ruddon RW (Eds.). Goodman and Gillman's the Pharmacological Basis of Therapeutics, $9^{\text {th }}$ ed., New York, USA: McGraw-Hill, 1996 1459-86. 